\title{
Erratum to: Decellularization Methods for Scaffold Fabrication
}

\section{Sweta K. Gupta, Narayan C. Mishra, and Archna Dhasmana}

Erratum to:

Methods in Molecular Biology

10.1007/7651_2017_34

The publisher regrets that an author was not mentioned in the chapter by mistake. The details of the author are provided below:

Archna Dhasmana - Department of Polymer and Process Engineering, Indian Institute of Technology, Roorkee, India 